\title{
PENINGKATAN KEMAMPUAN MENYUSUI PADA IBU POST PARTUM DI WILAYAH KERJA PUSKESMAS KOTABUMI II
}

\author{
Aryanti Wardiyah ${ }^{1}$, Rina Puspitasari ${ }^{2}$, Neta Susmarini ${ }^{3}$ \\ ${ }^{1}$ Dosen Akademi Keperawatan Malahayati Bandar Lampung \\ Email : gipho85@yahoo.com \\ ${ }^{2}$ Perawat Puskesmas Kalibalangan Kabupaten Lampung Utara \\ Email : rinapuspitasari334@gmail.com \\ ${ }^{3}$ Perawat Puskesmas Kotabumi II Kabupaten Lampung Utara \\ Email : netasusmarini1@gmail.com
}

\section{ABSTRACT : INCREASING BREASTFEEDING AT PUBLIC HEALTH SERVICES (PUSKESMAS KOTABUMI II)}

Background : Breastfeeding is role of a mother after delivering of baby. Based of pre-survey data from 2015 to 2016 at Public Health Services (Puskesmas Kotabumi II) recorded the postpartum had been increased from 9,41\% to 14,6\% while at Kotabumi II Public Health Center of although with lowest coverage but decreased coverge from year 2015 to in 2016 from 35,7\% to 21,3\%. Based on data from Kotabumi II Public Health Center troughout 2017 it is known 144 post partum mothers who exclusively breastfed only $19,4 \%$.

Puspose: Knowed effectively postpartum positioning and attachement education for increasing breastfeeding at Public Health Services (puskesmas Kotabumi II) North Lampung 20018.

Methods : This research was quantitative research, Quasi experimental design. The research conducted on postpartum as many as 34 respondents. Sampling technique used accidental sampling. Data collected by observation sheets. Data analysis performed univariate (mean) and bivariate (t test).

Results : Found in the study, the ability of breastfeeding in postpartum before giving health education with a mean value of 57.06 and standard deviation of 11.284 and after giving health education with a mean of 86.59 and standard deviation of 7.427 .

Conclusion : There is influence of health education to improve the ability of breastfeeding of post partum at Public Health Services (Puskesmas) Kotabumi II North Lampung in 2018. It is expected that health care provider to be an active role in giving information or health information in breastfeeding related to mother's knowledge and behavior in breastfeeding toward baby, follow-up such as periodic evaluation, so that the purpose of breastfeeding is achieved.

Keywords: Postpartum, Positioning, Attachment Education, Increasing Breastfeeding

\section{INTISARI: PENINGKATAN KEMAMPUAN MENYUSUI PADA IBU POST PARTUM DI WILAYAH KERJA PUSKESMAS KOTABUMI II}

Pendahuluan : Memberikan ASI merupakan tugas seorang ibu setelah tugas melahirkan bayi berhasil dilaluinya. Berdasarkan prasurvey di Puskesmas Kotabumi II pada ibu yang kontrol prenatal care di dapat yang masih memberikan air susu ibu (ASI) dari 10 ibu didapatkan 6 (60\%) yang tidak memberikan ASI. 
Tujuan : Diketahui pengaruh pendidikan kesehatan teradap kemampuan menyusui terhadap pada ibu post partum di Wilayah Kerja Puskesmas Kotabumi II Kabupaten Lampung Utara tahun 2018.

Metode : Penelitian ini penelitian kuantitatif, rancangan Quasi Eksperimen. Penelitian telah dilakukan bulan Februari-Maret 2018 di Wilayah Kerja Puskesmas Kotabumi II Kabupaten Lampung Utara tahun 2018. Populasi penelitian ibu post partum, berdasarkan ibu hamil trimester 3 atau yang akan bersalin dalam 3 bulan kedepan (Januari-Maret) sebanyak 98 orang, sampel 30 orang. Teknik Pengambilan sampel accidental sampling. Pengumpulan data menggunakan lembar observasi. Analisis data secara univariat dan bivariat (Uji t).

Hasil : Didapatkan dalam penelitian ini, kemampuan menyusui pada ibu postpartum sebelum diberikan pendidikan kesehatan dengan nilai mean 57,06 dan standar deviasi 11,284 dan setelah diberikan pendidikan kesehatan dengan nilai mean 86,59 dan standar deviasi 7,427.

Simpulan : Ada pengaruh pengaruh pendidikan kesehatan terhadap peningkatan kemampuan menyusui ibu post partum di Wilayah Kerja Puskesmas Kotabumi II Kabupaten Lampung Utara tahun 2018. Diharapkan petugas kesehatan lebih berperan aktif memberikan penyuluhan atau informasi kesehatan terhadap ibu menyusui terkait dengan pengetahuan dan perilaku menyusui ibu terhadap bayi, serta diadakan tindak lanjut misalnya evaluasi periodik, agar tujuan dari menyusui tercapai.

Kata kunci : Pendidikan kesehatan, tehnik menyusui, kemampuan menyusui, lbu post partum

\section{PENDAHULUAN}

Pembangunan secara umum sering diartikan sebagai upaya multidimensi untuk mencapai kualitas hidup seluruh penduduk yang lebih baik. Pembangunan kesehatan di Indonesia diselenggarakan secara menyeluruh dengan tujuan untuk meningkatkan kesadaran, kemauan dan kemampuan hidup sehat bagi setiap orang agar terwujud derajat kesehatan yang setinggi-tingginya (Dinas kesehatan Provinsi Lampung, 2016).

Dalam rangka menurunkan angka kesakitan dan kematian anak, United Nation Childrens Fund (UNICEF) dan World Health Organization (WHO) merekomendasikan sebaiknya anak hanya disusui air susu ibu (ASI) selama paling sedikit enam bulan. makanan padat seharusnya diberikan sesudah anak berumur 6 bulan dan pemberian ASI dilanjutkan sampai anak berumur 2 tahun (Kementerian kesehatan Republik Indonesia, 2017). Pedoman internasional yang menganjurkan pemberian ASI eksklusif selama 6 bulan pertama didasarkan pada bukti ilmiah tentang manfaat ASI bagi daya tahan tubuh bayi, pertumbuhan dan perkembangannya (Yuliarti, 2010). Pemberian ASI sangatlah baik untuk bayi, hanya sekitar 36\% bayi yang berusia 0-6 bulan di seluruh dunia disusui secara eksklusif selama periode 2007-2014. Sekitar 40\% bayi berusia 0-6 bulan disusui secara eksklusif (WHO, 2017).

Angka pemberian ASI eksklusif di Indonesia tahun 2015 pada bayi berumur 6 bulan mencapai angka $55,7 \%$. Terdapat 23 provinsi yang mempunyai presentase ASI eksklusif di atas angka Nasional $(55,7 \%)$ yang tertinggi di NTB $(85,9 \%)$ dan 
terendah Sulawesi Utara $(26,3 \%)$ dan Lampung mencapai 54,9\% merupakan 9 terendah dari seluruh provinsi di Indonesia (Kementerian kesehatan Republik Indonesia, 2016).

Tahun 2016, terjadi penurunan persentase bayi 0-5 bulan yang masih mendapat ASI eksklusif sebesar $54,0 \%$, sedangkan bayi yang telah mendapatkan ASI eksklusif sampai usia enam bulan adalah sebesar $29,5 \%$. Pencapaian tertinggi di Provinsi NTT sebesar 79,9\% dan terendah Provinsi Gorontalo sebesar $32,3 \%$ sedangkan provinsi Lampung sebesar $43,1 \%$ masih di bawah target pencapaian provinsi (Kemenkes, 2017).

Sementara itu, data yang dikeluarkan oleh Dinkes Provinsi Lampung bahwa pemberian ASI eksklusif pada bayi 0-6 bulan berfluktuatif, pada tahun 2012 sebesar 30,1\%, tahun 2013 kenaikan yang bermakna menjadi $42,0 \%$ dan tahun 2014 cakupan bayi mendapatkan ASI Ekslusif sebanyak 82,3\% namun di tahun 2015 cakupan ASI eksklusif mengalami penurunan menjadi $57,7 \%$ bayi dimana angka ini masih di bawah target yang diharapkan sebesar 80\% (Dinkes Lampung, 2016). Di tahun 2016 kembali mengalami penurunan menjadi sebesar $43,1 \%$ (Kementerrian kesehatan Republik Indonesia, 2017).

Ibu yang memberikan ASI eksklusif di Kabupaten Lampung Utara dari tahun 2012 sampai 2016 berkisar 20\%-70\%. Cakupan pemberian ASI eksklusif dari tahun 2012-2016 mengalami penurunan. Peningkatan yang signifikan terjadi di tahun 2011 sebesar $70.40 \%$ kemudian menurun kembali ditahun 2012 sebesar $59.80 \%$, dan menurun kembali pada tahun 2013 menjadi $51,00 \%$ dan tahun 2014 menjadi $42,20 \%$ namun terjadi sedikit meningkat di tahun 2015 yaitu 48,3\% sedangkan pada tahun 2016 cakupan ASI Ekslusif mengalami penurunan menjadi 43,2\% (Dinas kesehatan Provinsi Lampung, 2017).

Di Lampung Utara tahun 2015 jumlah bayi yang diberi ASI eksklusif sebesar $48,3 \%$ sedangkan target cakupan ASI eksklusif $80 \%$. Puskesmas Ulak Rengas Kecamatan Abung Tinggi yaitu 95,61\% dan cakupan terendah ada Puskesmas Negara Ratu hanya 9,41\% sedangkan di Puskesmas Kotabumi II sebesar 35,7\%. Ditahun 2016 cakupan pemberian ASI terendah masih di Puskesmas Negara Ratu namun mengalami peningkatan menjadi sebesar 14,6\% sedangkan Puskesmas Kotabumi II mengalami penurunan menjadi sebesar 21,3\% (Dinas Kesehatan Provinsi Lampung, 2017).

Dalam proses laktasi seringkali terjadi kegagalan baik dari bayi ataupun ibu. Salah satu faktor dari ibu yaitu cara menyusui yang tidak benar dapat menyebabkan puting susu nyeri/lecet dan payudara bengkak. Ibu-ibu tidak berhasil menyusui atau menghentikan menyusui lebih dini, karena tidak mengetahui cara-cara yang sebenarnya sangat sederhana, seperti cara menaruh bayi pada payudara ketika menyusui, isapan yang mengakibatkan puting terasa nyeri dan masih banyak lagi masalah yang lain. Hal ini dapat menimbulkan gangguan dalam proses menyusui, sehingga pemberian ASI menjadi tidak adekuat. Pemberian ASI yang idak adekuat dapat menyebabkan kekurangan nutrisi pada bayi dan bayi rentan terhadap penyakit yang pada akhirnya menyebabkan kematian bayi khususnya Bayi Baru Lahir (BBL) (Apriyani, Kristiyanti., \& Susiatmi, (2015).

Manfaat yang diperoleh dari menyusui bagi bayi tidak lepas dari tata cara atau proses menyusui yang 
benar pada bayi. Banyak ibu dalam menyusui tidak dilakukan dengan benar, bahkan banyak pula ibu yang tidak bersedia menyusui bayinya. Keberhasilan menyusui harus diawali dengan kepekaan terhadap waktu tepat saat pemberian ASI, yaitu dengan tanda-tanda antara lain berupa gerakan-gerakan memainkan mulut dan lidah atau memainkan tangan dimulut. Kepekaan terhadap waktu menyusui tidak cukup untuk keberhasilan menyusui. Kegagalan menyusui disebabkan oleh teknik dan posisi menyusui yang kurang tepat (Gunarsa, 2008); (Kumorojati, 2017).

Kesalahan terletak pada posisi menyusui dan langkah-langkah menyusui. Masalah tersering dalam menyusui adalah puting susu nyeri/lecet. Kebanyakan puting susu nyeri/lecet disebabkan oleh kesalahan memposisikan dan melekatkan bayi. Jika bayi melekat dengan sempurna atau ibu mendekap bayi sedemikian rupa sehingga menyebabkan puting menjadi nyeri, jika puting terus menerus tergesek oleh lidah dan langit-langit bayi puting dapat mengalami luka. Puting susu yang lecet dapat menyebabkan mastitis dan abses di payudara. Selain menyebabkan puting susu lecet teknik menyusui yang salah juga dapat mengakibatkan ASI tidak keluar optimal sehingga mempengaruhi produksi ASI selanjutnya atau bayi enggan menyusu (Aini, 2017).

Oleh karena itu ibu-ibu memerlukan bantuan agar proses menyusui lebih berhasil. Banyak alasan yang dikemukakan oleh ibuibu yang tidak menyusui bayinya antara lain ibu tidak memproduksi ASI yang cukup, melainkan karena ibu kurang percaya diri bahwa ASInya cukup untuk bayinya. Sehingga informasi mengenai cara menyusui yang benar dapat membantu ibu agar dapat menyusui lebih berhasil, sehingga bayi menghisap dengan baik dan produksi ASI cukup, serta dengan cara-cara menyusui yang baik dapat memberikan kenyamanan dalam menyusui, mencegah gangguan pada puting susu ibu, sehingga bayi mendapatkan cukup ASI, terhindar dari berbagai penyakit infeksi (Nurdiana, 2016).

Upaya untuk meningkatkan pengetahuan tentang manajemen laktasi adalah dengan memberikan penyuluhan. Manajemen laktasi meliputi perawatan payudara, praktek menyusui yang benar, serta dikenalinya masalah laktasi dan cara mengatasi. Memberikan informasi tentang menyusui yang benar pada ibu sangat penting demi suksesnya ibu dalam memberikan ASI. Seorang ibu perlu mendapat dukungan tentang cara menyusui yang benar. Cara meletakkan bayi pada payudara ketika menyusui berpengaruh terhadap keberhasilan menyusui. Teknik menyusui perlu diajarkan kepada ibu untuk mencegah kesulitan dalam pemberian ASI (Saraswati \& Mufdlilah (2014). Memberikan ASI merupakan tugas seorang ibu setelah tugas melahirkan bayi berhasil dilaluinya. Menyusui dapat merupakan pengalaman yang menyenangkan atau dapat menjadi pengalaman yang tidak nyaman bagi ibu dan bayi dikarenakan puting susu lecet, payudara bengkak, saluran susu terhambat, mastitis, dan absesny payudara. Hal ini dapat terjadi dikarenakan teknik menyusui yang tidak benar (Wagner, S, etc, 2019).

Menyusui dengan teknik yang tidak benar dapat mempengaruhi produk ASI selanjutnya dan bayi pun enggan menyusu sehingga bayi tidak menyusui secara efektif. Salah satu tidak efektif nya bayi dalam menyusui diantaranya adalah dagu 
bayi tidak menempel pada payudara ibu, bayi hanya menghisap puting susunya saja, dan areola tidak masuk di mulut bayi (Saraswati \& Mufdlilah (2014).

Penelitian Himawati, 2012 dalam Suryaningsih 2018 pengaruh pendidikan kesehatan tentang teknik menyusui terhadap pengetahuan dan perilaku teknik menyusui pada ibu primipara di BPS Kecamatan Kalibawang Kulonprogo tahun 2011. Hasil penelitian menunjukkan bahwa ada pengaruh kesehatan pendidikan tentang teknik menyusui tentang pengetahuan menyusui teknik $(\mathrm{t}=$ 670; $\mathrm{p}(0,00)<0,05)$ dan perilaku $(\mathrm{t}=$ -1081); p $(0,00)<0,05)$ dari ibu primipara Disarankan agar bidan secara aktif memberikan pendidikan kesehatan tentang pengetahuan dan perilaku ibu dalam menyusui bayinya dan bahwa mereka mengadakan evaluasi berkala untuk mencapai tujuan akhir menyusui

Penelitian Marshella (2014) pendidikan kesehatan tehnik menyusui dengan benar terhadap peningkatan kemampuan menyusui pada ibu post partum normal di RSUD. Dr. Soewondo Kendal. Berdasarkan hasil penelitian ini dapat disimpulkan bahwa pendidikan kesehatan tehnik menyusui dengan benar berpengaruh dalam peningkatan kemampuan tehnuk menyusui dengan benar pada pasien ibu post partum normal di RSUD Dr. H. Soewondo Kendal.

Penelitian Lidiyana (2017) pengaruh pendidikan kesehatan tentang teknik menyusui terhadap pengetahuan pada ibu hamil trimester III di Wilayah Kerja Puskesmas Baki Sukoharjo. Hasil Penelitian menunjukkan rata-rata pengetahuan ibu hamil sebelum diberikan pendidikan kesehatan tentang teknik menyusui adalah sebesar 59,50 dan rata-rata pengetahuan ibu hamil setelah diberikan diberikan pendidikan kesehatan sebesar 77,17 dengan nilai signifikan 0,000 atau $\mathrm{p}<0,05$.

Berdasarkan data tahun 2015 terlihat pada Puskesmas Negara Ratu walaupun merupakan Puskesmas dengan cakupan terendah namun tahun 2016 mengalami peningkatan yaitu dari 9,41\% menjadi $14,6 \%$ sedangkan pada Puskesmas Kotabumi II walaupun bukan Puskesmas dengan cakupan terendah namun mengalami penurunan cakupan dari tahun 2015 ke tahun 2016 yaitu dari $35,7 \%$ menjadi $21,3 \%$ Berdasarkan data dari Puskemas Kotabumi II sepanjang tahun 2017 diketahui dari 144 ibu post partum yang memberikan ASI secara eksklusif hanya sebanyak 19,4\%.

$$
\text { Peneliti }
$$

melakukan wawancara yang dilakukan pada tangal 4-8 Desember 2017 terhadap 6 ibu post partum, dari 6 ibu postpartum sebanyak 5 orang primipara dan 1 orang multipara, dan dari 6 ibu tersebut, sebanyak 83,3\% mengatakan mengalami luka lecet pada puting payudara. Dari 6 ibu tersebut tidak mengetahui tentang tekhnik menyusui dengan benar. Dari 6 ibu tersebut sebanyak 4 ibu telah memberikan susu lewat botol.

Dari observasi yang dilakukan di wilayah kerja Puskesmas Kotabumi II, kepada setiap ibu post partum yang akan pulang kerumah petugas memberikan pengetahuan tentang manfaat menyusui, hal-hal yang harus diperhatikan oleh ibu saat masa nifas dirumah seperti kebersihan diri dan konsumsi makanan. Petugas kesehatan sudah pernah memberikan penyuluhan tentang tekhnik menyusui namun sudah lama dan tidak dilakukan secara rutin sehingga tidak optimal, untuk itu perlu dilakukan pendidikan kesehatan kembali kepada ibu 
postpartum demi keberhasilan ASI eksklusif.

Berdasarkan fenomena diatas, penulis merasa tertarik untuk meneliti lebih jauh tentang pengaruh pendidikan kesehatan terhadap kemampuan menyusui pada ibu post partum di Wilayah Kerja Puskesmas Kotabumi II Kabupaten Lampung Utara tahun 2018.

\section{METODE PENELITIAN}

Jenis penelitian yang digunakan dalam penelitian ini adalah kuantitatif yaitu jenis penelitian untuk mendapatkan gambaran yang akurat dari sebuah karakteristik masalah yang berbentuk mengklasifikasikan suatu data (Notoatmodjo, 2012). Dalam penelitian ini untuk mengetahui pengaruh pendidikan kesehatan tentang tehnik menyusui terhadap peningkatan kemampuan menyusui pada ibu post partum di Wilayah Kerja Puskesmas Kotabumi II Kabupaten Lampung Utara tahun 2018. Kemampuan menyusui diukur sebelum dan sesudah diberikan pendidikan kesehatan.

Menurut Riyanto (2011) populasi adalah keseluruhan subjek penelitian. Jadi, populasi penelitian dapat disimpulkan sebagai subjek penelitian yang mengenainya dapat diperoleh dari data yang dipermasalahkan. Sesuai dengan tujuan yang ingin dicapai, populasi pada penelitian ini adalah seluruh ibu post partum di Wilayah Kerja Puskesmas Kotabumi II Kabupaten Lampung Utara Tahun 2018., dimana berdasarkan ibu hamil trimester 3 atau yang akan bersalin dalam 3 bulan kedepan (Januari-Maret) sebanyak 98 orang.

HASIL

\section{Analisis Univariat}

Tabel 1

Kemampuan menyusui pada ibu post partum primi sebelum diberikan pendidikan kesehatan di Wilayah Kerja Puskesmas Kotabumi II Kabupaten Lampung Utara tahun 2018

\begin{tabular}{cccccc}
\hline $\begin{array}{c}\text { Kemampuan } \\
\text { menyusui }\end{array}$ & Mean & SD & Min & Max & N \\
\hline $\begin{array}{c}\text { Sebelum Pendidikan } \\
\text { kesehatan }\end{array}$ & 57,06 & 11,284 & 36 & 76 & 34 \\
\hline
\end{tabular}

Berdasarkan tabel 4.1 menunjukkan bahwa sebelum diberikan pendidikan kesehatan, berdasarkan hasil olah data yang dilakukan, diperoleh kemampuan menyusui sebelum pendidikan kesehatan adalah 57,06 dengan standar deviasi 11,284. 
Tabel 2

Kemampuan menyusui pada ibu post partum primi setelah diberikan pendidikan kesehatan di Wilayah Kerja Puskesmas Kotabumi II Kabupaten Lampung Utara tahun 2018

\begin{tabular}{llllll}
\hline \multicolumn{1}{c}{$\begin{array}{c}\text { Kemampuan } \\
\text { menyusui }\end{array}$} & Mean & SD & Min & Max & N \\
\hline $\begin{array}{l}\text { Setelah pendidikan } \\
\text { kesehatan }\end{array}$ & 86,59 & 7,427 & 72 & 100 & 34 \\
\hline
\end{tabular}

Berdasarkan tabel 4.2 menunjukkan bahwa setelah diberikan pendidikan kesehatan, berdasarkan hasil olah data yang dilakukan, diperoleh rata-rata 86,59 dengan standar deviasi 7,427.

\section{Persyaratan analisis}

Pengujian analisis pada penelitian ini jelas sudah dipenuhi karena sampel penelitian diambil secara acak terhadap ibu post partum primipara. Untuk mengetahui tingkat ketepatan dalam pengambilan sampel, maka dilakukan pengujian persyaratan analisis yang lain yaitu uji normalitas dan uji homogenitas. Selanjutnya, uji normalitas dan uji homogenitas diuraikan sebagai berikut:

\section{Uji Normalitas}

Uji normalitas variabel pengaruh terapi terhadap mual muntah dipergunakan Menggunakan nilai skewness dan standar errornya, bila nilai skewness dibagi standar error menghasilkan angka $\leq 2$, maka distribusinya normal (Hastono, 2016).

Tabel 3

Uji Normalitas data penelitian

\begin{tabular}{lcccl}
\hline \multicolumn{1}{c}{ Variabel } & $\begin{array}{c}\text { Skewnes } \\
\text { s }\end{array}$ & Std. Error & $\begin{array}{c}\text { Skewness : } \\
\text { Std.Error }\end{array}$ & Ket \\
\hline $\begin{array}{l}\text { Sebelum } \\
\text { pendidikan } \\
\text { kesehatan }\end{array}$ & 0,098 & 0,403 & 0,24 & $\begin{array}{l}\text { Norm } \\
\text { al }\end{array}$ \\
$\begin{array}{l}\text { Setelah } \\
\text { pendidikan } \\
\text { kesehatan }\end{array}$ & 0,141 & 0,403 & 0,34 & $\begin{array}{l}\text { Norm } \\
\text { al }\end{array}$ \\
\hline
\end{tabular}

Berdasarkan tabel 4.3 diatas masing-masing variabel mempunyai nilai skewness dan standar eror, bila nilai skewness di bagi standar erornya menghasilkan angka $\leq 2$, maka distribusi normal, bila data berdistribusi normal maka dapat dilanjutkan untuk uji ( $t$ independent)

\section{Uji Homogenitas}

Uji homogenitas variansi data dilakukan dengan mempergunakan pengujian lewat komputer (Levene Test). Kriteria yang digunakan melalui pengujian lewat komputer adalah: Jika nilai sig. yang diperoleh dalam tampilan Output SPSS > a, maka variansi setiap sampel sama (homogen) dan Jika nilai sig. yang diperoleh dalam tampilan Output 
SPSS < a, maka variasi setiap sampel tidak sama (tidak homogen) (Hastono, 2016). Berdasarkan pengujian homogenitas variansi kelompok-kelompok menghasilkan tampilan Output SPSS dalam lampiran, diperoleh nilai sig. adalah $(0,103$ dan $0,220>0,05)$. Berdasarkan pengujian lewat komputer tersebut di atas, dapat disimpulkan bahwa variasi skor-skor bersifat homogen.

\begin{abstract}
Analisis Bivariat
Analisis yang dilakukan untuk mengetahui pengaruh pendidikan kesehatan kemampuan menyusui dengan benar dengan menggunakan uji statistik $t$ dengan taraf kesalahan (a) $5 \%$ kemudian diprogram dengan sistem komputer menggunakan program SPSS for windows.
\end{abstract}

Tabel 4

Pengaruh pendidikan kesehatan terhadap peningkatan kemampuan menyusui pada ibu post partum primi di Wilayah Kerja Puskesmas Kotabumi II Kabupaten Lampung Utara tahun 2018

\begin{tabular}{lcccccc}
\hline Kelompok & $\mathrm{N}$ & $\begin{array}{c}\text { Beda } \\
\text { Mean }\end{array}$ & SD & t-test & $\begin{array}{c}\text { P- } \\
\text { Value }\end{array}$ & $\begin{array}{c}\text { Keteranga } \\
\mathrm{n}\end{array}$ \\
\hline $\begin{array}{l}\text { Kemampuan } \\
\begin{array}{l}\text { menyusui sebelum - } \\
\text { setelah pendidikan } \\
\text { kesehatan }\end{array}\end{array}$ & 34 & $\begin{array}{c}29,52 \\
9\end{array}$ & $\begin{array}{c}8,80 \\
9\end{array}$ & $\begin{array}{l}19,54 \\
8\end{array}$ & 0,000 & $\begin{array}{c}\text { Ada } \\
\text { pengaruh }\end{array}$ \\
\hline
\end{tabular}

Berdasarkan tabel 4.5 diatas, hasil uji statistik didapatkan $t$-test $>\mathrm{t}$ tabel, 19,548>1.684, $p$-value $=0,000$ ( $p$-value $<\alpha=0,05$ ) yang berarti ada pengaruh pendidikan kesehatan terhadap peningkatan kemampuan menyusui pada ibu post partum primi di Wilayah Kerja Puskesmas Kotabumi II Kabupaten Lampung Utara tahun 2018. Berdasarkan hasil terlihat bahwa, pada kelompok setelah diberikan pendidikan kesehatan memiliki kenaikan tingkat kemampuan menyusui dengan selisih 29,529 point.

\section{Pembahasan \\ Kemampuan menyusui sebelum diberikan pendidikan kesehatan Berdasarkan hasil olah data yang dilakukan, diperoleh kemampuan menyusui sebelum pendidikan kesehatan adalah 57,06 dengan standar deviasi 11,284.}

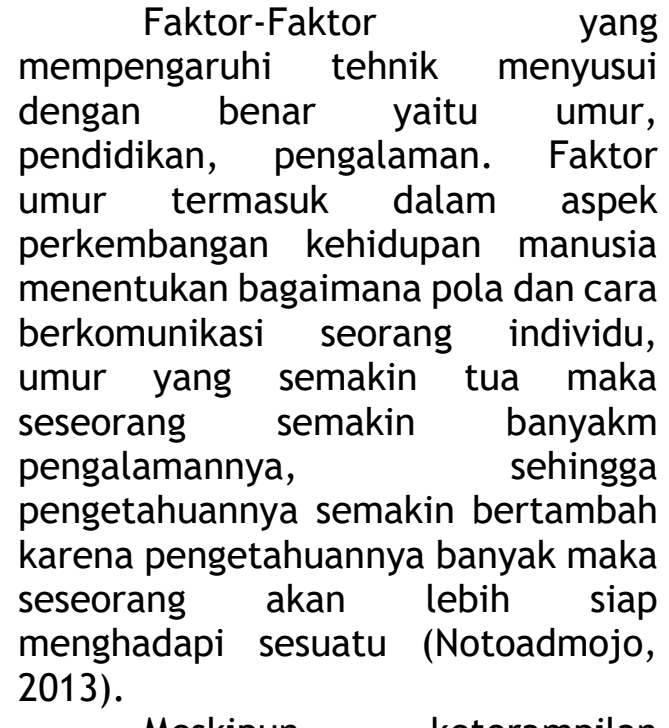

Meskipun keterampilan menyusui dapat dikuasai secara alamiah pada setiap ibu, ibu harus tetap memahami tehnik menyusui bayi yang baik dan benar. Sering kali kegagalan menyusui disebabkan karena salah dalam memosisikan dan meletakkan bayi. Puting ibu menjadi lecet sehingga ibu jadi segan 
menyusui, produksi ASI berkurang sehingga bayi menjadi malas menyusu (Suryoprajogo, 2009); (Widyaningrum, 2016).

Hasil penelitian didukung dengan hasil penelitian (Wagner, S, etc, 2019).yang menyatakan bahwa tingkat pengetahuan ibu tentang cara menyusui yang benar sebagian besar kurang berhubungan dengan praktik ibu menyusui yang sebagian besar kurang. Penelitian sesuai dengan hasil penelitian yang dilakukan oleh Rahayuyang menyatakan bahwa gambaran praktik ibu tentang cara menyusui yang benar sebagian besar ibu praktik ibu menyusui kurang benar sebanyak 19 orang $(59,38 \%)$.

Penelitian yang dilakukan oleh Himawati (2012) pengaruh pendidikan kesehatan tentang teknik menyusui terhadap pengetahuan dan perilaku teknik menyusui pada ibu primipara di BPS Kecamatan Kalibawang Kulonprogo tahun 2011. Diketahui responden sebelum dilakukan pemberian pendidikan kesehatan (pretest) mempunyai pengetahuan baik sebesar 11 responden $(36,7 \%)$, cukup 16 responden $(53,3 \%)$ dan kurang 3 responden $(10 \%)$.

Menurut pendapat peneliti, kurangnya pengetahuan ibu tentang cara tehnik menyusui dengan benar antara lain, kurang nya informasi dari tenaga kesehatan kepada ibu, kurang jelasnya informasi yang disampaikan oleh tenaga kesehatan kepada ibu, kurang kemampuan dari ibu untuk memahami informasi yang diberikan di karenakan tingkat pendidikannya masih rendah, makin tinggi pendidikan seseorang makin mudah menerima informasi, sehingga makin banyak pula pengetahuan yang dimiliki. Pendidikan bertujuan untuk mengubah pengetahuan/pengertian, pendapat, konsep-konsep, sikap, dan persepsi serta menanamkan tingkahy laku atau kebiasaan yang baru pada pendidikan rendah serta menanamkan tingkah laku atau kebiasaan yang baru pada pendidikan rendah serta meningkatkan pengetahuan yang cukup/kurang. Sebelum dilakukan pendidikan kesehatan tentang cara menyusui yang benar terlihat bahwa kemampuan ibu post partum kurang mengenai cara menyusui yang benar dengan nilai rata-rata 57,06. Hal ini sesuai dengan tujuan pendidikan yang menyatakan bahwa pendidikan kesehatan diberikan agar terjadi perubahan ke arah lebih baik, meskipun perubahan perilaku tidak selalu terjadi segera setelah belajar. Oleh karena itu, evaluasi dapat dilanjutkan dengan melakukan kunjungan rumah.

\section{Kemampuan menyusui setelah diberikan pendidikan kesehatan}

Berdasarkan hasil olah data yang dilakukan, diperoleh rata-rata 86,59 dengan standar deviasi 7,427.

Faktor-faktor yang mempengaruhi pengetahuan dibagi menjadi faktor internal yang meliputi: pendidikan, pekerjaan, dan umur sedangkan faktor eksternal meliputi: faktor lingkungan dan social ekonomi. Pendidikan seseorang yang tinggi akan mudah menerima hal-hal yang baru dan mudah menyesuaikan dengan perubahan baru. Pengalaman sangat berpengaruh terhadap tingkat pengetahuan seseorang, jika pendidikan tinggi maka pengalaman akan semakin banyak (Wawan dan Dewi, 2010).

Penelitian yang dilakukan oleh Himawati (2012) pengaruh pendidikan kesehatan tentang teknik menyusui terhadap pengetahuan dan perilaku teknik menyusui pada ibu primipara di BPS Kecamatan Kalibawang Kulonprogo tahun 2011. Diketahui setelah diberikan kesehatan (posttest) responden 
mempunyai pengetahuan baik sebesar 29 responden $(96,7 \%)$, cukup 1 responden $(3,3 \%)$.

Hasil penelitian ini sesuai dengan teori yang menyatakan bahwa pengetahuan merupakan hasil penginderaan individu yang berupa fakta-fakta dan informasi baru yang mampu menarik atau mempengaruhi individu tersebut. Seseorang yang mempunyai sumber informasi yang lebih banyak akan memberikan pengetahuan yang lebih jelas (Notoatmodjo, 2010).

Hasil penelitian di dukung oleh penelitian yang dilakukan oleh Bantarti Wisni, (2012) tentang pengaruh pendidikan kesehatan terhadap pengetahuan dan praktik ibu menyusui tentang cara menyusui yang benar pada ibu menyusui di Desa Nolokerto Kecamatan Kaliwungu Kabupaten Kendal, menyatakan bahwa setelah dilakukan pendidikan kesehatan tentang cara menyusui diperoleh bahwa sebagian besar pengetahuan ibu baik sebanyak 23 responden $(64,2 \%)$ dan praktik ibu sebagian besar menjadi baik sebanyak 20 responden $(58,5 \%)$.

Menurut pendapat peneliti, peningkatan kemampuan ibu setelah dilakukan pendidikan kesehatan terjadi disebabkan karena mayoritas ibu post partum sudah memahami dan mengerti tentang cara menyusui yang benar setelah diberikan pendidikan kesehatan. Hal ini sesuai dengan tujuan pendidikan kesehatan yaitu untuk menjembatani kesenjangan antara informasi kesehatan dan praktek kesehatan, yang memotivasi seseorang untuk memperoleh informasi dan berbuat sesuatu sehingga dapat menjaga dirinya menjadi lebih sehat dengan menghindari kebiasaan yang buruk dan membentuk kebiasaan yang baik untuk kesehatan.

\section{Analisis Bivariat}

Berdasarkan hasil uji statistik didapatkan $t_{\text {-test }}>\mathrm{t}$ tabel, 19,548> 1.684, $p$-value $=0,000$ ( $p$-value $<a=$ 0,05 ) yang berarti ada pengaruh pendidikan kesehatan terhadap peningkatan kemampuan menyusui pada ibu post partum primi di Wilayah Kerja Puskesmas Kotabumi II Kabupaten Lampung Utara tahun 2018. Berdasarkan hasil terlihat bahwa, pada kelompok setelah diberikan pendidikan kesehatan memiliki kenaikan tingkat kemampuan menyusui dengan selisih 29,529 point.Menurut peneliti pendidikan kesehatan merupakan upaya persuasi atau pembelajaran kepada masyarakat mau melakukan tindakan (praktik) untuk memelihara (mengatasi masalah-masalah), dan meningkatkan kesehatannya. Pendidikan kesehatan dapat mempengaruhi seseorang termasuk juga perilaku seseorang akan pilihan hidup terutama kemampuan menyusui, pendidikan kesehatan berarti bimbingan yang diberikan seseorang terhadap perkembangan orang lain menuju ke arah suatu citacita tertentu.

Keberhasilan suatu pendidikan kesehatan kesehatan dapat dipengaruhi oleh faktor penyuluh, sasaran dan proses penyuluh. Pendidikan kesehatan kesehatan adalah kegiatan pendidikan kesehatan, yang dilakukan dengan menyebarkan pesan, menanamkan keyakinan, sehingga masyarakat tidak saja sadar, tahu dan mengerti, tetapi juga mau dan bisa melakukan suatu anjuran yang ada hubungannya dengan kesehatan. Hal ini sesuai dengan teori pengetahuan yang mencakup dalam domain kognitif (Notoatmodjo, 2012) yaitu : tahu (mengingat suatu materi yang telah dipelajari sebelumnya) dan memahami (kemampuan untuk menjelaskan secara benar tentang obyek yang diketahui dan dapat 
menginterpretasikan materi secara benar). Peningkatan pengetahuan ini dapat dipengaruhi oleh beberapa faktor, salah satu faktornya adalah faktor penyuluhan dari tenaga kesehatan.

Sejalan dengan penelitian yang dilakukan oleh penelitian Marshella (2014) pendidikan kesehatan tehnik menyusui dengan benar terhadap peningkatan kemampuan menyusui pada ibu post partum normal di RSUD. Dr. Soewondo Kendal. Ada pengaruh pemberian tehnik menyusui dengan benar terhadap peningkatan kemampuan ibu tentang cara menyusui pada ibu post partum normal di RSUD dr. H. Soewondo Kendal dengan hasil nilai $\mathrm{p}$ value 0,000 .

Berdasarkan hasil penelitian diketahui bahwa secara keseluruhan responden mengalami peningkatan kemampuan dalam menyusui, namun dengan nilai yang berbeda-beda. Dengan nilai peningkatan terendah sebesar 12 point sebanyak 2 orang dengan usia < 20 tahun yaitu 18 dan 19 tahun sedangkan sebanyak 1 orang dengan peningkatan tertinggi sebesar 52 point sebanyak 1 orang dengan usia 35 tahun. Menurut peneliti pada seseorang memasuki usia dewasa sehingga cara berfikir akan lebih matang dan lebih siap untuk menikah, berperan sebagai orang tua dalam melakukan perawatan pada bayi khususnya pemberian ASI melalui teknik menyusui yang benar., semakin cukup umur tingkat kematangan dan kekuatan seseorang dalam berfikir dan bekerja. Usia sangat mempengaruhi seseorang dalam mengambil keputusan, karena tidak semua golongan usia dapat menyatakan kesiapannya dalam menyusui. usia $>20$ merupakan usia dewasa. Usia dewasa mempunyai kematangan fisik dan psikologis sehingga dianggap mampu menghadapi berbagai masalah terutama dalam hal menyusui.

Pengetahuan tentang teknik menyusui adalah pemahaman responden tentang teknik menyusui yang diperoleh dari sumber informasi ataupun pengalaman mereka yang didapatkan di lingkungan. Ketika responden mendapati orang di sekitar mereka menyusui, maka perilaku yang diperoleh dari situasi tersebut menjadi sumber informasi bagi ibu hamil tentang teknik menyusui yang benar. Hal ini berhubungan dengan penelitian tentang hubungan informasi dan pengalaman terhadap pengetahuan yang mengemukakan bahwa salah satu faktor yang mempengaruhi pengetahuan adalah pengalaman. Dengan semakin meningkatnya usia maka semakin banyak pengalaman seseorang sehingga membawa pengaruh terhadap kehidupannya.

Kesiapan menyusui pada ibu primigravida berbeda-beda, hal ini dapat dilihat dari niat seorang ibu, karena apabila niat tertanam kuat pada seorang ibu merupakan kunci sukses untuk menyusui. Karena apabila niat baik disalurkan pada suatu hal yang baik, dapat mempengaruhi hasil yang baik, begitu juga dalam hal menyusui. Perubahan kesiapan menunjukkan adanya pengaruh pemberian pendidikan kesehatan, hal ini disebabkan karena upaya dan usaha dari responden untuk memahami materi tentang cara menyusui yang terdapat pada leaflet. Selain itu, responden juga berusaha untuk menjawab posttest yang diberikan sesuai dengan materi yang terdapat pada leaflet. Sehingga terlihat dala penelitian bahwa secara keseluruhan terjadi peningkatan kemampuan pada responden walaupun peningatan tersebut berbeda-beda, ada yang mengalami peningkatan sedikit 
namun juga ada yang mengalami peningkatan cukup banyak.

Menurut peneliti kemampuan menyusui merupakan salah satu faktor yang menentukan keberhasilan dalam pemberian ASI. Kemampuan menyusui dapat berfungsi sebagai pendorong ibu sehingga keberhasilan atau pencapaian ASI ekslusif dapat terlaksana. Pendidikan kesehatan kesehatan identik dengan pendidikan kesehatan karena keduanya beriorentasi kepada perilaku yang diharapkan yaitu perilaku sehat, sehingga mempunyai kemampua mengenal masalah kesehatan dirinya, keluarga dan kelompoknya dalam meningkatkan kesehatannya. Pendidikan kesehatan kesehatan merupakan upaya untuk memberikan pengalaman belajar atau menciptakan suatu kondisi bagi individu, kelompok dan masyarakat untuk menerapkan cara-cara hidup sehat. pendidikan kesehatan kesehatan masyarakat di selenggarakan guna meningkatkan kemampuan menyusui, kesadaran, kemauan dan kemampuan masyarakat untuk hidup sehat dan aktif berperan serta dalam upaya kesehatan.

Menurut pendapat peneliti Pendidikan kesehatan yang dilakukan dalam penelitian ini telah memberikan perubahan pada kemampuan menyusui. Manfaat yang diperoleh dari menyusui bagi bayi tidak lepas dari tata cara atau proses menyusui yang benar pada bayi. Banyak ibu dalam menyusui tidak dilakukan dengan benar, bahkan banyak pula ibu yang tidak bersedia menyusui bayinya. Keberhasilan menyusui harus diawali dengan kepekaan terhadap waktu tepat saat pemberian ASI, yaitu dengan tandatanda antara lain berupa gerakangerakan memainkan mulut dan lidah atau memainkan tangan dimulut. Kepekaan terhadap waktu menyusui tidak cukup untuk keberhasilan menyusui. Kegagalan menyusui disebabkan oleh teknik dan posisi menyusui yang kurang tepat

Kemampuan ibu dalam menyusui dengan benar khususnya bagi ibu primipara sangat mendukung keberhasilan ibu dalam menyusui dengan teknik yang benar. Seorang ibu dengan bayi pertamanya mungkin akan mengalami masalah ketika menyusui yang sebetulnya hanya karena tidak tahu cara-cara menyusui yang benar. Cara menyusui berpengaruh terhadap keberhasilan menyusui. Bidan serta petugas kesehatan yang lain harus melakukan pendampingan dan memberikan dukungan selama menyusui. Untuk mencapai keberhasilan menyusui, bidan harus memberikan bimbingan cara menyusui yang benar, sehingga ibu tidak mengalami masalah selama menyusui dan bayi pun mendapatkan ASI Eksklusif.

Hasil pengetahuan ibu sebelum diberi pendidikan kesehatan baik, walaupun pengetahuan ibu primipara tentang ASI dan teknik menyusui baik, tetapi perilaku menyusui ibu primipara sebelum diberi pendidikan kesehatan hasilnya belum tentu baik atau tidak sesuai teknik. Setelah dilakukan penyuluhan oleh petugas kesehatan hasilnya terjadi peningkatan pengetahuan dan keterampilan menyusui pada ibu primipara. Peran petugas kesehatan tentang pendidikan kesehatan sangat penting untuk meningkatkan pengetahuan, wawasan dan perubahan perilaku ibu menyusui. Apalagi dengan kondisi ibu-ibu setempat yang kurang bisa menerima danmenerapkan informasi dengan cepat, pendidikan kesehatan yang berulang-ulang sangat diperlukan untuk menanamkan nilai-nilai kesehatan pada ibu-ibu menyusui. Bimbingan secara terus-menerus dalam pemberian pendidikan 
kesehatan sangat berpengaruh terhadap perubahan perilaku individu, dengan usaha pemberian pendidikan kesehatan yang terusmenerus, diharapkan nilai-nilai kesehatan tertanam dengan baik, derajat kesehatan menjadi baik dan akhirnya ibu mampu mandiri dalam mengatasi masalah kesehatan

Peningkatan kemampuan ibu setelah dilakukan pendidikan kesehatan terjadi disebabkan karena mayoritas ibu post partum sudah memahami dan mengerti tentang cara menyusui yang benar setelah diberikan pendidikan kesehatan. Hal ini sesuai dengan tujuan pendidikan kesehatan yaitu untuk menjembatani kesenjangan antara informasi kesehatan dan praktek kesehatan, yang memotivasi seseorang untuk memperoleh informasi dan berbuat sesuatu sehingga dapat menjaga dirinya menjadi lebih sehat dengan menghindari kebiasaan yang buruk dan membentuk kebiasaan yang baik untuk kesehatan.

Adanya pendidikan kesehatan dapat menambah pengetahuan ibu post partum sesuai dengan teori bahwa pengetahuan merupakan hasil penginderaan individu yang berupa fakta-fakta dan informasi baru yang mampu menarik atau mempengaruhi individu tersebut. Seseorang yang mempunyai sumber informasi yang lebih banyak akan memberikan pengetahuan yang lebih jelas

\section{KESIMPULAN}

Berdasarkan hasil penelitian dan pembahasan diambil beberapa kesimpulan sebagai berikut

1. Kemampuan menyusui pada ibu postpartum primi sebelum diberikan pendidikan kesehatan adalah 57,06 dengan standar deviasi 11,284.
2. Kemampuan menyusui pada ibu postpartum primi setelah diberikan pendidikan kesehatan adalah 86,59 dengan standar deviasi 7,427.

3. Ada pengaruh pengaruh pendidikan kesehatan terhadap peningkatan kemampuan menyusui ibu post partum primi di Wilayah Kerja Puskesmas Kotabumi II Kabupaten Lampung Utara tahun 2018.

\section{SARAN}

Berdasarkan pada kesimpulan yang telah diuraikan oleh penulis diatas, saran yang mungkin dapat dijadikan pertimbangan dan masukkan bagi institusi kesehatan adalah sebagai berikut :

a. Lebih meningkatkan intensitas pendidikan kesehatan seperti pendidikan kesehatan dilaksanakan $2 x$ dalam sebulan dan diberikan secara rutin oleh petugas kesehatan terutama pendidikan kesehatan berkaitan dengan kesehatan reproduksi.

b. Memberi informasi kepada ibu poostpartum primi tentang kemampuan menyusui yang benar sehingga membantu kemampuan ibu dalam memberikan ASI.

c. Diharapkan hasil penelitian ini dapat dijadikan landasan untuk suatu program kegiatan bagi masyarakat khususnya bagi ibu postpartum primi, seperti diadakannya arisan yang dapat diisi dengan kegiatan pendidikan kesehatan.

d. Peneliti mengharapkan agar bidan lebih berperan aktif dalam memberikan penyuluhan atau informasi kesehatan terhadap ibu menyusui primipara maupun multipara terkait dengan pengetahuan dan perilaku menyusui ibu 
terhadap bayi, serta diadakan tindak lanjut misalnya evaluasi periodik, agar tujuan dari menyusui itu benar-benar tercapai

\section{DAFTAR PUSTAKA}

Aini, L. N. (2017). Hubungan Antara Sikap Ibu Primipara Dalam Pemberian Asi Dengan Teknik Menyusui Yang Benar Pada Balita Usia 0-24 Bulan. Jurnal Keperawatan Dan Kebidanan, 7(1).

Apriyani, N., Kristiyanti, R., \& Susiatmi, S. A. (2015). 1 Pengetahuan Ibu Nifas tentang Teknik Menyusui dengan kejadian putting susu lecet. Jurnal Ilmiah Kesehatan (JIK), 6(1).

Dinas kesehatan Provinsi Lampung (2016). Profil kesehatan provinsi lampung, 2016.

Dinas kesehatan Provinsi Lampung, (2017). Profil Dinas Kesehatan Kabupaten Lampung Utara 2017.

Gunarsa, S. D. (2008). Psikologi perkembangan anak dan remaja. BPK Gunung Mulia.

Kementerian kesehatan Republik Indonesia, (2016). Buku Kesehatan Ibu Dan Anak. Kementrian Kesehatan Ri Dan Jica. Jakarta.

Kementrian Kesehatan, Republik Indonesia, (2017). Data dan Informasi Profil Kesehatan Indonesia tahun 2016. Kementrian Kesehatan Republik Indonesia, Pusdatin Kemenkes RI.

Kumorojati, R. (2017). Gambaran Pengetahuan Ibu Menyusui Tentang Teknik Menyusui Yang Benar Di Puskesmas Pakualaman Yogyakarta. Media Ilmu Kesehatan, 6(1), 76-82.
Lidiyana, I. A. (2017). Pengaruh Pendidikan Kesehatan Tentang Teknik Menyusui Terhadap Pengetahuan Pada Ibu Hamil Trimester III Di Wilayah Kerja Puskesmas Baki Sukoharjo (Doctoral dissertation, Universitas Muhammadiyah Surakarta).

Marshella, A. A. P. (2014). Pendidikan Kesehatan Tehnik Menyusui Dengan Benar Terhadap Peningkatan Kemampuan Menyusui Pada Ibu Post Partum Normal Di Rsud. Dr. Soewondo Kendal. Karya IImiah S. 1 Ilmu Keperawatan.

Notoatmodjo, S. (2010). Metodologi penelitian kesehatan.

Notoatmodjo, S. (2012). Promosi kesehatan dan perilaku kesehatan.

Nurdiana, I. (2016). Hubungan Tingkat Pengetahuan Ibu Dan Ketersediaan Fasilitas Penunjang Asi Eksklusif Dengan Pemberian Asi Di Wilayah Kerja Puskesmas Bonorowo Kabupaten Kebumen (Doctoral Dissertation, Universitas Muhammadiyah Surakarta).

Riyanto, A. (2011). Aplikasi metodologi penelitian kesehatan.

Saraswati, E. R., \& Mufdlilah, M. (2014). Pengaruh Penyuluhan Cara Menyusui yang Benar terhadap Perilaku Pemberian ASI Minggu Pertama pada Ibu Nifas di RS PKU Muhammadiyah Yogyakarta (Doctoral dissertation, STIKES'Aisyiyah Yogyakarta). 
Suryaningsih, C., Fitriani, H., \&

Budiarti, C. C. (2018). PENGARUH PENDAMPINGAN TEKNIK MENYUSUI TERHADAP PERUBAHAN PANDANGAN BUDAYA DAN KEPERCAYAAN IBU DALAM PEMBERIAN ASI DI RUANG PERINATALOGI RSUD CIBABATCIMAHI TAHUN 2017. Jurnal Kesehatan Kartika, 12(2), 70-80.

Suryoprajogo, N. (2009). Keajaiban Menyusui. Yogyakarta.

Fitramaya.

Wagner, S., Kersuzan, C., Gojard, S., Tichit, C., Nicklaus, S., Thierry, X., ... \& de Lauzon-Guillain, B. (2019). Breastfeeding initiation and duration in France: The importance of intergenerational and previous maternal breastfeeding experiencesresults from the nationwide ELFE study. Midwifery, 69, 67-75.

Wawan, A., \& Dewi, M. (2010). Teori dan pengukuran pengetahuan, sikap dan perilaku manusia. Yogyakarta: Nuha Medika, 15-20.

WHO, U., \& Mathers, C. (2017). Global strategy for women's, children's and adolescents' health (2016-2030). Organization, 2016(9).

Widyaningrum, L. A. (2016). Kejadian Puting Lecet Pada Ibu Primipara Berbasis Promosi Kesehatan Teknik Menyusui Yang Benar Dengan Pendekatan Health Belief Model (Studi Di Bps As-Syifa Husada Kabupaten Malang) (Doctoral Dissertation, University Of Muhammadiyah Malang).
Yuliarti, N. (2010). Keajaiban ASI makanan terbaik untuk kesehatan, kecerdasan dan kelincahan si kecil. Penerbit Andi. 